\title{
Structure analysis and optimal design of the vibrating screen girder of hoisting machinery
}

\author{
Qiulan Guo \\ School of Architecture Engineering, Xinyu University, Jiangxi 338004, China \\ 514149150@qq.com
}

Keywords: Main girder of hoisting machinery; ANSYS; The finite element model; the optimal design.

\begin{abstract}
This paper analyzed the structure and mechanical load of the main girder of hoisting machinery, taking the construction hoisting machinery as the breakthrough point, establish finite element model of main girder by ANSYS, analyze the structure natural frequency and strength of the main girder. Then an optimal design of main girder was made based on the mathematical model of the quality of the main girder as the objective function.
\end{abstract}

\section{Introduction}

Hoisting machinery is the machinery equipment which can transport bodies vertically or horizontally in a certain range. With the development of a large-scale high-rise buildings and large steel public facilities, Construction hoisting machinery, which is a very important auxiliary tool in the production of modernization construction, is widely used in the production activities in various fields, especially suitable for large span of installations of the steel structure. The main girder as the main component of the crane is crucial for the overall safety and economy.Therefore, the demand for screening machinery capacity is more and more, the research and manufacture of large vibrating screen is particularly important.

\section{The finite element model}

Structure analysis. Construction of the bridge crane structure including the side beams, girders, tonnage equipment, lifting the car, running wheels, data plate device and electrical equipment parts, etc. Crane operation process, the bridge on both sides along the elevated track vertical run, lifting trolley along the girder on the horizontal run orbit, thereby lifting space below materials.In the vibrating screen structure, main girder ends on the vibrating screen is a consolidation of the left and right sides is symmetrical and side plate structure, the girder ends are in bondage to the side panel all the ends of the girder each have two vibrator, vibration direction just perpendicular to the plane of the vibrator in the main girder function, also is the direction of the vibration of the vibrating screen.

Load analysis. Vibrating screen in normal work, main girder under the following load:One, the main girder's own gravity;Second, installed on the main girder of eccentric vibrator excitation;Third, vibrating screen, vibration inertia force of main girder itself;Four, vibrating screen weight reaction force of main girder[1].The above four force of main girder of gravity and the sieve things force of main girder is very small relative to the exciting force and inertial force, negligible,So here just for exciting force and inertial force are analyzed, and analysis of main girder said the most exciting force and inertial force, for the purpose of below intensity.Calculate the biggest inertial acceleration are obtained $a_{\max }=30 \mathrm{~m} / \mathrm{s}^{2}$,Can be used in the analysis of load.

A total of four on vibrating screen girder vibrator, each side has two, and symmetric distribution.Each vibrator by eight bolted on main girder, and the eight bolts evenly distributed, So each vibrator vibration force of main girder by the eight bolts evenly transfer, the equivalent of main girder under eight are the same size and direction of concentrated force.Calculated vibrator on each bolt passed by the maximum vibration force to load can be used for analysis. 
The finite element model. Finite Element Method (FEM) is a kind of the use of relatively simple problems instead of complicated problems and then solve the modern numerical methods,Its basic idea is through the multidimensional continuous elastomer mechanical calculation into co., the calculation of multiple nodes, and then complete the complex structural mechanics analysis[2, 3].

AS Known from the analysis of the structure and the load,Finite element method for bridge, gantry crane and tower crane metal structure analysis, explore the stress and deformation law, provide reference for improving structure design.The structure of the vibrating screen girder are left and right sides is symmetrical, constraint and load,Here you can take half of the main girder structure finite element model is established.When modeling to simplify the model, even as some holes, bolt holes to ignore, fillet with right Angle instead of directly.After simplification, the use of ANSYS software, APDL language, the establishment of a three-dimensional finite element model are shown in figure 1 below.

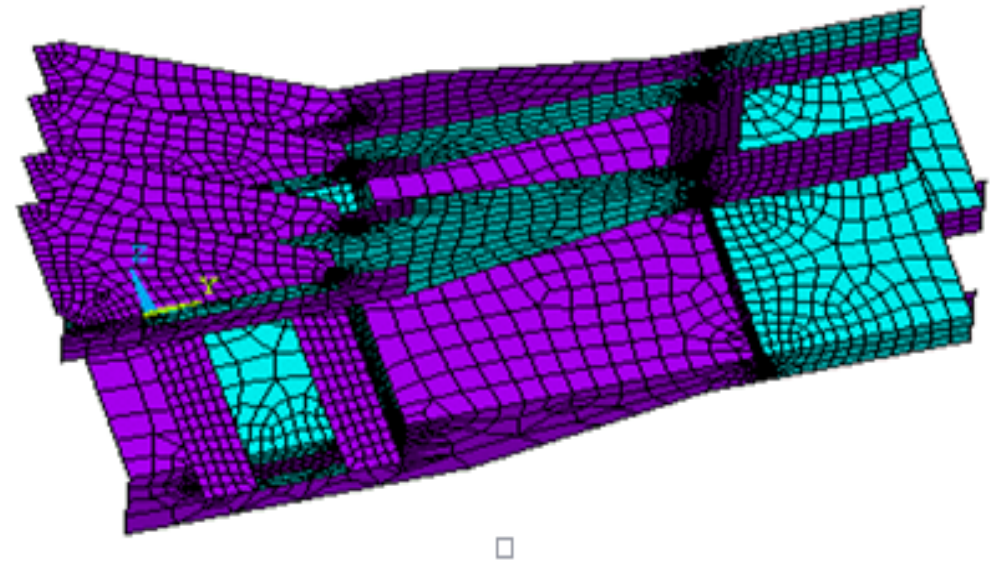

Figure 1 Three-dimensional finite element model

Applying constraint and load boundary conditions. Main girder simplified into a cone beam.Hoisting load refers to load due to lifting heavy objects, including the weight of the lifting and fetch device, etc.Usually can be hoisting wire rope etc, the quality of the weight of the heavy weight and the car only to determine the lifting load.

Hoisting load refers to load due to lifting heavy objects, including the weight of the lifting and fetch device, etc. Gravity load for the distribution of force, through the processing material properties are defined in the material density, and the weight of the girder by applying gravity acceleration effect.

By the overall structure of the vibrating screen, main girder on the vibrating screen, its both ends fixed on the side panel of vibrating screen, therefore, be bound by all;The half of the model for the main girder structure, so the main girder in symmetrical end surface are symmetry constraint.In the analysis of load, the maximum acceleration of the main girder, so girders are inertial load;Main girder at the same time also by vibrator excitation force, each by vibrator by 8 bolts on the main girder, expressed as eight concentration,So said the main girder will be 16 concentrated force, point in the center of the bolt is empty.Main girder structure under load and boundary conditions. The structure of the main girder under load and boundary condition is shown in figure 2 .

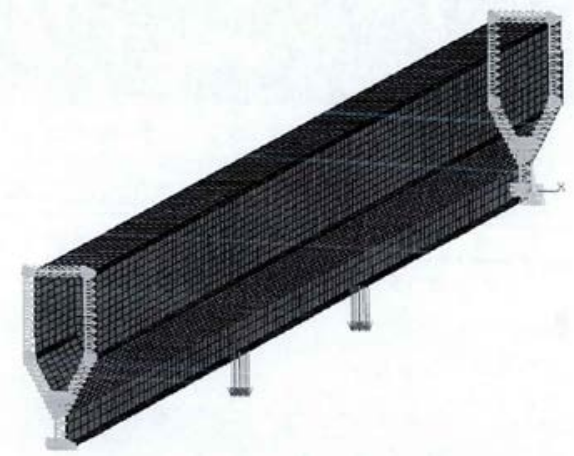

Figure 2 The girder under load and boundary conditions 


\section{Natural frequency and strength analysis}

Using software ANSYS solver to get natural frequency of the main girder as shown in table 1, And the resulting equivalent stress distribution of girders.

Table 1 The natural frequency of the main girder $(\mathrm{Hz})$

\begin{tabular}{cccccccc}
\hline Order & Frequency & Order & Frequency & Order & Frequency & Order & Frequency \\
\hline 1 & 134 & 6 & 317 & 11 & 461 & 16 & 516 \\
2 & 188 & 7 & 393 & 12 & 462 & 17 & 520 \\
3 & 195 & 8 & 412 & 13 & 492 & 18 & 532 \\
4 & 213 & 9 & 424 & 14 & 502 & 19 & 533 \\
5 & 280 & 10 & 433 & 15 & 511 & 20 & 534 \\
\hline
\end{tabular}

The natural frequency of the main girder and the resulting equivalent stress distribution of girders. By girder inherent frequency table and equivalent stress distribution, Girder first-order minimum frequency freq_1 $=139 \mathrm{hz}$, main girder on the maximum equivalent stress for the smax $=40.568 \mathrm{MPa}$. According to the calculated main girder of main girder is much higher than the working frequency of $13.3 \mathrm{~Hz}$ only natural frequency; Girder material is just, check the manual, according to the fourth strength theory to calculate the maximum allowable stress, is greater than the maximum equivalent stress $40.568 \mathrm{MPa}$. Visible in this structure tend to be more safe, main girder can be a first order optimization for the main girder structure frequency and the maximum allowable stress as a constraint condition in optimizing the structure of the main girder.

\section{Summary}

The optimization design, on the premise of safety work of girders and minimize the quality of main girder, and reduce the cost of main girder as the purpose of the optimization design as much as possible.

So, the optimization mathematical model of the girder total quality $\mathrm{W}$ as objective function, thickness and width for the boundary constraint conditions, the maximum allowable stress and the first order frequency for performance constraints.For the convenience of establishing mathematical model of the mould, can make:

$$
\begin{aligned}
& x_{1}=t 1, x_{2}=t 2, x_{3}=t 3, x_{4}=t 4 ; \\
& x_{5}=\text { wide } 1, x_{6}=\text { wide } 2 ;
\end{aligned}
$$

Check the steel material handbook. Volume 1. Carbon structural steel "[8], the thickness of the Q235 steel specified part of the value (unit: $\mathrm{mm}$ ): 10.0, 11.0, 12.0, 14.0, 16.0, 18.0, 20.0, 22.0, 25.0, 28.0, 30.0, 32.0, 30.0, 32.0, 40.0, 45.0, 50.0, 55.0. About the thickness of the plate girders of the scope of four design variables $x_{1}, x_{2}, x_{3}, x_{4}$ can be defined according to the specified value. For the other two design variables for the width of the floor, there is no fixed standard, the scope for as long as the appropriate value from each on its initial value as the upper and lower. By the main girder structure size:For maximum wide2 initial value is $150 \mathrm{~mm}, 150 \mathrm{~mm}$, so desirable its $170 \mathrm{~mm}$, maximum minimum of $130 \mathrm{~mm}$. As manual for roundness, various sizes of girders are shown in table 2 below. The optimized girder to the natural frequency of $145.84 \mathrm{~Hz}$, farther from the work frequency of the main girder, and more security; The maximum equivalent stress of main girder is $52.131 \mathrm{MPa}$, still less than the allowable safety stress of main girder, can work safety; Main girder total quality declined from $3.521 \mathrm{t}$ to $3.521 \mathrm{t}$, a $12.1 \%$ reduction in quality, meet the optimization goal, the optimization results. 
Table 2 The optimization results in (mm)

\begin{tabular}{ccccccc}
\hline & $x_{1}$ & $x_{2}$ & $x_{3}$ & $x_{4}$ & $x_{5}$ & $x_{6}$ \\
\hline The design variables & {$[35,45]$} & {$[25,35]$} & {$[15,25]$} & {$[12,20]$} & {$[200,300]$} & {$[130,170]$} \\
\hline The initial value & 40 & 30 & 20 & 16 & 200 & 150 \\
\hline The optimal value & 36.1 & 28.01 & 18.24 & 20.524 & 267.84 & 156.86 \\
\hline Roundness value & 34 & 27 & 17 & 19 & 261 & 196 \\
\hline
\end{tabular}

Table 2 can be, Natural frequency of the main girder model increased from the original $134 \mathrm{hz}$ to $134 \mathrm{hz}$, increased by 5.9\%; Girder model of maximum equivalent stress, increased from the original 41.578 Mpa to 53.465 Mpa, increased by $28.6 \%$, but there is still no more than the allowable stress of material $56 \mathrm{Mpa}$; The total mass of the main girder model reduce from $3.431 \mathrm{t}$ to $3.252 \mathrm{t}$, fell by $5.2 \%$. After round the value and the optimal value of comparison, while increasing the maximum equivalent stress and natural frequency becomes but quality also becomes so overall or comply with the design requirements.

\section{References}

[1] Xiang Shao-jiang,Qiu Feng,Zhao Hai-feng. ANSYS senior structure finite element analysis method and example applications[M].The second edition. Beijing: China water conservancy press. 2009:87-132.

[2] Game studio, ANSYS 9.0 classic products based tutorials and example explanation[M].Beijing: China water conservancy and hydropower press. 2012:146-223.

[3]Gong Shu-guang,Huang Yun-hai.The finite element analysis with ANSYS APDL programming and advanced application[M].Beijing: Mechanical industry publishing house. 2011:2011-168.

[4]Yu. Sun.Guo. The development and utilization of panzhihua west slag field feasibility study[M].Kunming university of science and master thesis, 2012.

[5]zheng.Gang. The use of new energy-saving materials and the development of reading architecture [J].Energy and environment,2010(5) :86-88.

[6]Xue.Yong.jie. The performance and application of new energy-saving building materials[J]. Guangdong chemical,20011(2): 82-83. 